\title{
Seleção de Acessos e Progênies de Citrullus spp. para Resistência a Três Potyvirus*
}

\author{
Lindomar M. da Silveira ${ }^{1 * *}$, Manoel A. de Queiróz ${ }^{2}$, J. Albérsio de A. Lima ${ }^{3 * * *}$, Maria Z. de Negreiros ${ }^{1}$, \\ Najara F. Ramos ${ }^{3 * * *}$ \& Aline K. Q. do Nascimento ${ }^{3 * * *}$
}

${ }^{1}$ Escola Superior de Agricultura de Mossoró, ESAM, BR 110, km 47, Bairro Costa e Silva,CEP 59625-900, Mossoró, RN, e-mail: lindomarmaria@yahoo.com.br; ${ }^{2} \mathrm{DTCS} / \mathrm{UNEB}, \mathrm{Av}$. Edgard Chastinet Guimarães, s/n, Cx. Postal 171,

Bairro São Geraldo, CEP 48905-680, Juazeiro, BA, e-mail: manoelabilio@ @erra.com.br; ${ }^{3} \mathrm{UFC}$, Lab. de

Virologia Vegetal, Cx. Postal 6046, Fortaleza, CE, e-mail: albersio@ufc.br.

(Aceito para publicação em 28/06/2005)

Autor para correspondência: Lindomar Maria da Silveira

SILVEIRA, L.M., QUEIRÓZ, M.A., LIMA, J.A.A., NEGREIROS, M.Z., RAMOS, N.F. \& NASCIMENTO, A.K.Q. Seleção de acessos e progênies de Citrullus spp. para resistência a três potyvirus. Fitopatologia Brasileira 30:394-399. 2005.

RESUMO

Visando selecionar acessos e progênies de melancia (Citrullus spp.) como fontes de resistência aos potyvirus: Papaya ringspot virus - tipo watermelon (PRSV-W), Watermelon mosaic virus (WMV) e Zucchini yellow mosaic virus (ZYMV), oito genótipos foram avaliados, sendo seis dos acessos (87-019, 87-029, 91-080, PI-244018, 91-043 e PI-195927) e dois do acesso PI-244019 (PI-244019A e PI-244019B) do Banco Ativo de Germoplasma (BAG) de cucurbitáceas do Nordeste brasileiro, da Embrapa Semi-Árido em Petrolina-PE. Também foram avaliadas progênies endogâmicas e de polinização livre derivadas desses acessos. As avaliações foram realizadas em de casa de vegetação, mediante inoculações mecânicas, e avaliação por Elisa, no Laboratório de Virologia Vegetal da UFC. As plantas não infetadas foram selecionadas e cultivadas na Estação Experimental de Bebedouro na Embrapa Semi-Árido em Petrolina-PE, onde ocorreram inoculações naturais de vírus por vetores. Foram constatadas plantas não infetadas com o PRSV-W nos acessos 87-019, PI-244019A, 91-080, PI-244018, PI-244019B e PI195927; plantas não infetadas com o WMV nos acessos 87-019 e 87-029 e plantas não infetadas com o ZYMV nos acessos PI244019A, 87-029, 91-080, 91-043, PI-244019B e PI-195927. As progênies apresentaram comportamento diferenciado, com percentagem de plantas selecionadas variando de 20 a 100\% nas progênies avaliadas para resistência a PRSV-W e 60 a $100 \%$ nas progênies avaliadas para resistência a WMV. Nenhuma das progênies testadas apresentou resistência ao ZYMV, evidenciando possível diferença entre a resistência ao PRSV-W e ao WMV apresentada nas progênies e a resistência apresentada ao ZYMV, visto que as progênies foram submetidas ao mesmo número de autofecundações.

Palavras-chave adicionais: cucurbitáceas, seleção para melhoramento, PRSV-W, WMV, ZYMV.

\begin{abstract}
Citrullus spp. accession and progeny selection for resistance to three potyviruses

Six watermelon (Citrullus spp.) accessions (87-019, 87-029, 91-080, PI-244018, 91-043 and PI-195927) and two samples (PI-244019A and PI-244019B) from the acession PI-244019B from Embrapa Cucurbit Germplasm Bank in PetrolinaPE, Northeast of Brazil were evaluated in an attempt to select accessions and progenies of watermelon as sources of resistance to Papaya ringspot virus - type watermelon (PRSV-W), Watermelon mosaic virus (WMV) and Zucchini yellow mosaic virus (ZYMV). Endogamic and open pollinated progenies from these accessions were also evaluated for resistance to PRSV-W, WMV and ZYMV. The evaluations were carried out in a greenhouse at the Plant Virus Laboratory of the Federal University of Ceará where the plants were mechanically inoculated and serological screened by Elisa. The selected plants were grown in the Experimental Station of Bebedouro in Petrolina-PE, where the virus inoculations were made, naturally, by vectors. According to the results, plants were not infected by PRSV-W in the following accessions: 87-019, PI-244019A, 91-080, PI244018, PI-244019B and PI-195927; plants were not infected by WMV in the accessions: 87-019 and 87-029; and plants were not infected by ZYMV in the accessions: PI-244019A, 87-029, 91-080,91-043, PI-244019B and PI-195927. The progenies showed differentiated behavior with the percentage of selected plants ranging from 20 to $100 \%$ for PRSV-W and 60 to $100 \%$ for WMV. The progenies evaluated against ZYMV did not show resistant plants. Therefore, it can be postulated that resistance for PRSV-W and WMV in the progenies differs from that for ZYMV, since all progenies were submitted to the same number of self-pollinations.
\end{abstract}

Additional keywords: cucurbitaceous, screening for virus resistance, PRSV-W, WMV, ZYMV.

\section{INTRODUÇÃO}

* Parte da Dissertação de Mestrado do primeiro autor. Escola Superior de Agricultura de Mossoró (2004).

***Bolsista da CAPES

****Bolsistas do CNPq
A melancia [Citrullus lanatus (Thumb.) Matsum \& Nakai], membro da família Cucurbitaceae, está entre as cinco mais importantes hortaliças cultivadas no Brasil. Sua área 
plantada em 2002 foi em torno de 82.000 ha e sua produção de 80 mil ton (FAO, 2003). Dada a importância econômica da cultura no país, estratégias têm sido adotadas para tornar o produto mais competitivo, especialmente no controle de pragas e doenças. Os genótipos de melancia utilizados nos cultivos comerciais são poucos e foram desenvolvidos para condições japonesas e americanas e posteriormente introduzidos no Brasil (Costa \& Pinto, 1997). Este fato acarreta gastos com defensivos, uma vez que quando cultivadas em condições ambientais diferentes daquelas para as quais foram desenvolvidas, as variedades tornam-se suscetíveis ao ataque de pragas e doenças. Por outro lado, os genótipos de melancia disponíveis na agricultura tradicional do Nordeste brasileiro são muitos e apresentam grande variabilidade para características diversas, inclusive resistência às principais doenças que se manifestam na cultura, incluindo as viroses ocasionadas pelos vírus da família Potyviridae, gênero Potyvirus: Papaya ringspot virus - tipo watermelon (PRSV-W), Watermelon mosaic virus (WMV) e Zucchini yellow mosaic virus (ZYMV) (Oliveira et al., 2000, 2002; Queiróz et al., 2002). Essa variabilidade está preservada no Banco Ativo de Germoplasma (BAG) de cucurbitáceas para o Nordeste brasileiro, localizado na Embrapa Semi-Árido em Petrolina-PE (Queiróz, 1998). As viroses ocasionadas por PRSV-W, WMV e ZYMV são consideradas fatores limitantes ao cultivo da melancia em áreas produtoras, pois além de originar decréscimo na produtividade podem ocasionar sérios comprometimentos à qualidade dos frutos (Oliveira et al., 2000. 2002; Lima et al., 2002). A identificação de fontes de resistência e sua transferência para tipos comerciais constituem uma importante alternativa de controle para vírus de planta em geral e em especial para os pertencentes ao gênero Potyvirus por apresentarem grande variabilidade de estirpes, e seus hospedeiros possuírem comportamento diferenciado para as mesmas (Bhargava \& Bhargava, 1976). Nos acessos de melancia provenientes da agricultura tradicional do Nordeste brasileiro, características como peso do fruto, cores interna e externa e teor de sólidos solúveis, encontram-se mais próximas daquelas apresentadas pelos genótipos comerciais (Silveira, 2002). Mesmo promissores, esses acessos apresentam segregação para resistência, tolerância e suscetibilidade a vírus, inviabilizando seu uso direto em programas de melhoramento, tornando necessária à obtenção de linhagens homozigotas para resistência a vírus.

Assim, o presente trabalho teve como objetivo selecionar acessos e suas respectivas progênies para resistência aos potyvirus PRSV-W, WMV e ZYMV, a partir de amostra de acessos promissores previamente selecionados para essa característica, visando o emprego das mesmas em programas de melhoramento.

\section{MATERIAL E MÉTODOS}

Nove genótipos de melancia foram avaliados para resistência aos potyvirus PRSV-W, WMV e ZYMV, sendo seis dos acessos (87-019, 87-029, 91-080, PI-244018, 91-043 e PI-195927) e dois do acesso PI-244019 (PI-244019A e PI244019B). Esses acessos incluem representantes das espécies C. lanatus (87-019, 87-029, 91-080 e 91-043), e Citrullus colocynthis (L.) Schrad. (PI-195927), e o híbrido natural entre as duas espécies $C$. lanatus var. citroides (Bailey) Mansf. (PI244019, PI-244018), do BAG de cucurbitáceas para o Nordeste brasileiro. Os acessos do BAG compreendem, desde introduções de origem africana até acessos coletados na agricultura tradicional.

\section{Avaliação dos Acessos em Casa de Vegetação}

As avaliações quanto à resistência aos potyvirus foram realizadas em condições de casa de vegetação, no Laboratório de Virologia Vegetal, da Universidade Federal do Ceará (UFC), no período de junho a agosto de 2002 e em condições de campo na Estação Experimental de Bebedouro na Embrapa Semi-Árido em Petrolina-PE, no período de agosto a outubro do mesmo ano. Sementes dos acessos foram semeadas, em vasos preenchidos com solo e esterco de curral esterilizados, na proporção de duas partes de solo para uma parte de esterco mantidos em casa de vegetação. Após a germinação, foram cultivadas quatro plantas por vaso, sendo utilizadas 32 plantas de cada acesso, das quais oito plantas foram inoculadas mecanicamente com cada um dos vírus mantidos no Banco Ativo de Vírus do Laboratório de Virologia Vegetal da UFC, os quais foram também utilizados por Oliveira (2000), e oito foram mantidas sem inoculação para serem utilizadas como controle (plantas sadias). As inoculações foram realizadas utilizando extratos de plantas de abobrinha (Cucurbita pepo L.) 'Caserta' sistemicamente infetadas com cada vírus, preparadas na presença de solução tampão $0,05 \mathrm{M}$ de fosfato de potássio, pH 7,5, através da maceração de tecido foliar infetado, na proporção de $1,0 \mathrm{~g}$ de tecido para 2,0 $\mathrm{ml}$ de solução.

Uma primeira inoculação foi realizada na fase inicial de desenvolvimento das plantas, antes do surgimento da primeira folha definitiva, oito a dez dias após o plantio, e uma segunda, 15 dias após a primeira, apenas nas plantas que não apresentaram sintomas. Dez dias após a segunda inoculação, as plantas, com ou sem sintomas, foram testadas por "enzyme linked immunosorbent assay" (Elisa) indireto (Almeida, 2001) contra anti-soros específicos para os vírus. Uma planta foi considerada infetada quando o teste de Elisa apresentou absorbância superior a duas vezes a média da absorbância das plantas sadias, conforme metodologia utilizada no Laboratório de Virologia Vegetal da UFC.

\section{Avaliação dos Acessos em Condições de Campo}

As avaliações em condições de campo consistiram em transplantar para uma área experimental de $117 \mathrm{~m}^{2}$ as 26 plantas dos acessos 87-019, PI-244019, 87-029 e 91-080, selecionados por sua resistência em casa de vegetação e cultivá-las sem o uso de inseticidas, permitindo visitação e alimentação dos insetos vetores. Dessa forma, do acesso 87019 foram transplantadas duas plantas selecionadas pela resistência ao PRSV-W, e três plantas selecionadas pela 
resistência ao WMV; do acesso PI-244019A, foram transplantadas três plantas selecionadas pela resistência ao PRSV-W e quatro plantas selecionadas pela resistência ao ZYMV; do acesso 87-029, foram transplantadas quatro plantas selecionadas pela resistência ao PRSV-W, três plantas selecionadas pela resistência ao WMV e quatro plantas selecionadas pela resistência ao ZYMV; e do acesso 91-080 foram transplantadas três plantas selecionadas pela resistência a PRSV-W. As plantas foram submetidas a polinizações artificiais (auto-fecundações) (Dias et al., 1999), para obtenção de progênies endogâmicas, sendo também mantidas progênies de polinização livre, que são predominantemente de meios-irmãos (Ferreira, 2000). Durante o desenvolvimento das plantas em campo, foram coletadas amostras de folhas e frutos, com e sem sintomas, para serem testadas por Elisa, contra anti-soros para PRSV-W, WMV e ZYMV. Amostragens periódicas em campos de melancia e meloeiro (Cucumis melo L.) na referida área, nos últimos anos, demonstraram a presença de vetores, assim como a presença dos vírus em questão (dados não publicados). As plantas selecionadas dos acessos PI-244018, 91-043, PI-244019B e PI-195927 não puderam ser transplantadas, pois não sobreviveram devido a danos sofridos durante o transporte. Como testemunha, seis plantas de melancia 'Crimson Sweet', foram distribuídas aleatoriamente entre as plantas dos acessos selecionadas em casa de vegetação.

\section{Avaliação de Progênies}

No período de setembro a dezembro de 2003, progênies provenientes de plantas com resistência em casa de vegetação e em condições de campo, para PRSV-W dos acessos 87-019 e PI-244019, para WMV dos acessos 87-019, 87-029 e PI244019 e para ZYMV dos acessos 87-029, PI-195927 e PI244019, foram testadas em casa de vegetação através de inoculação artificial. Também foram testadas progênies provenientes de plantas que não foram avaliadas em casa de vegetação ou em campo, para PRSV-W dos acessos 91-043, PI-195927 e 91-080, para WMV dos acessos 91-043 e 91080 e para o ZYMV do acesso 91-080. Todas as plantas foram avaliadas, diariamente, quanto a apresentação de sintomas e testadas por Elisa indireto, 30 dias após a primeira inoculação, contra os anti-soros específicos.

As progênies que confirmaram a resistência a um dos vírus observada nos genitores, assim como aquelas cuja sorologia confirmou a ausência de infecção para o outro vírus inoculado, foram selecionadas e transplantadas para o campo visando a obtenção de mais uma geração de endogamia nas progênies.

\section{RESULTADOS E DISCUSSÃO}

\section{Comportamento dos Acessos}

$\mathrm{Na}$ avaliação dos acessos foram encontradas plantas com resistência a um ou mais de um dos potyvirus testados. Resistência a apenas um potyvirus: Acesso PI-244018 - duas plantas resistentes ao PRSV-W, acesso 91080 - três plantas resistentes ao PRSV-W e acesso 91-043 - cinco plantas resistentes ao ZYMV. Acessos com resistência a dois potyvirus: Acesso 87-019 - duas plantas com resistência ao PRSV-W e três plantas resistentes ao WMV; PI-244019B duas plantas resistentes ao PRSV-W e seis plantas resistentes ao ZYMV, e PI-195927 - uma planta resistente ao PRSV-W e três plantas resistentes ao ZYMV. Acessos com resistência aos três potyvirus: PI-244019A e 87-029. Quando avaliados por Oliveira (2000), os acessos 91-080 e PI-244019 apresentaram plantas suscetíveis ao PRSV-W, com sintomas variando de mosaico leve a severo, e os acessos PI-244019, 91-080 e 91-043 apresentaram plantas resistentes ao WMV. Por outro lado, todos os acessos apresentaram plantas resistentes ao ZYMV, demonstrando consistência nos resultados somente com os acessos 87-029 e PI-195927, indicando variabilidade genética com possível segregação de plantas para resistência e suscetibilidade, entre plantas de um mesmo acesso.

O fato de os acessos avaliados serem compostos por misturas de sementes e, nas duas avaliações, terem sido avaliadas amostras distintas de um mesmo acesso, justifica a inconsistência nos resultados. Também é possível que, nos acessos onde houve confirmação de resultados, ocorra uma maior frequiência de alelos para a característica estudada, levando diferentes amostragens a resultados semelhantes, tornando necessária a obtenção e avaliação de progênies, acompanhando a genealogia das mesmas e combinando o trabalho de melhoramento com a avaliação para resistência aos vírus, até a obtenção de homozigose para os alelos que controlam a resistência. Essa situação será mais simples quando a característica for controlada por apenas um alelo, recessivo ou dominante (Webb, 1979; Wang et al., 1984) e mais complexa quando o controle da resistência depender de mais de um alelo (Danin-Poleg et al., 1997).

Vale salientar que foram avaliados acessos provenientes de um largo espectro, incluindo representantes de diferentes espécies do gênero Citrullus (acessos coletados na agricultura tradicional do Nordeste brasileiro), $C$. colocynthis (espécie de origem africana, bastante diferenciada da melancia cultivada) e C. lanatus var. citroides (híbrido natural formado pelo cruzamento entre as duas espécies mencionadas). Foram encontrados genótipos com resistência múltipla ou isolada nos acessos introduzidos, tanto da espécie C. colocynthis (PI-195927 para PRSV-W e ZYMV) quanto da espécie C. lanatus var. citroides (PI-244019 e PI-244018 para PRSV-W e ZYMV). Por outro lado, também foram encontradas plantas resistentes nos acessos originados da agricultura tradicional do Nordeste (87-019 para PRSV-W e WMV, 87-029 para PRSV-W, WMV e ZYMV, 91-080 para PRSV-W e 91-043 para ZYMV) (Tabela 1). Outro ponto a ser destacado é que genótipos promissores foram encontrados em acessos provenientes de diferentes regiões do Nordeste, sendo dois no Semi-Árido, (87-019 e 87-029 de Petrolina-PE e Paulistana-PI, respectivamente), um do município de Paraibano-MA (91-080) e outro do município de ItaguaçuBA (91-043), demonstrando que os alelos de resistência estão 
dispersos em populações tradicionais em vários pontos do Nordeste brasileiro. De acordo com Silveira (2002), nos acessos provenientes da agricultura tradicional, as características de peso do fruto, cores interna e externa e teor de sólidos solúveis estão mais próximas daquelas apresentadas pelos genótipos comerciais, particularmente a 'Crimson Sweet', variedade predominante nos cultivos comerciais da região Nordeste, do que nos acessos introduzidos. Esses dados aliados ao fato de os acessos coletados na agricultura tradicional serem adaptados às condições ambientais locais, aumentam a viabilidade de uso dos mesmos como fontes de resistência a viroses em programas de melhoramento de melancia, desde que se obtenham progênies homozigotas para as diversas fontes pesquisadas.

Plantas do acesso 87-029 não infetadas em casa de vegetação quando cultivadas em campo apresentaram resultado positivo em Elisa para PRSV-W, WMV e ZYMV, sendo a presença de cada vírus detectada em plantas separadas, não ocorrendo infecção mista (Tabela 2). Esses dados evidenciam a presença dos vírus e dos seus vetores naturais no campo. Na seleção em casa de vegetação, embora cada acesso tenha sido avaliado para resistência aos três vírus, cada planta foi avaliada individualmente para apenas um dos vírus. Ao serem transplantadas para o campo, as plantas não infetadas em casa de vegetação foram submetidas à possibilidade de inoculação natural com todos vírus através dos seus vetores naturais, uma vez que não foi realizado nenhum controle químico de vetores e os mesmos estão presentes em condições naturais, sobrevivendo, inclusive, em hospedeiros silvestres (Lima et al., 1997; Yuki, 1999; Silva et al., 2000).

É importante enfatizar que os potyvirus podem apresentar grande variabilidade biológica entre isolados de uma mesma espécie, com seus hospedeiros apresentando

TABELA 1 - Reação de acessos de melancia (Citrullus lanatus, C. colocynthis e C. lanatus var. citroides) avaliados em casa de vegetação para resistência a Papaya ringspot virus, tipo watermelon (PRSV-W), Watermelon mosaic virus (WMV) e Zucchini yellow mosaic virus (ZYMV). Laboratório de Virologia Vegetal da UFC. Fortaleza,CE. 2002

\begin{tabular}{|c|c|c|c|}
\hline \multirow{2}{*}{ Acesso/ espécie de Citrullus } & \multicolumn{3}{|c|}{ Reação aos vírus inoculados } \\
\hline & PRSV $-W^{1}$ & WMV $^{1}$ & ZYMV $^{1}$ \\
\hline 87-019/ Citrullus lanatus & $6 / 8$ & $5 / 8$ & $8 / 8$ \\
\hline PI-244019A / C. lanatus var. citroides & $6 / 8$ & $7 / 8$ & $4 / 8$ \\
\hline 87-029/ C. lanat us & $4 / 8$ & $5 / 8$ & $4 / 8$ \\
\hline $91-080 /$ C. lanatus & $5 / 8$ & $8 / 8$ & $8 / 8$ \\
\hline PI-244018/ C. lanatus var. citroides & $6 / 8$ & $8 / 8$ & $8 / 8$ \\
\hline $91-043$ / C. lanatus & $8 / 8$ & $8 / 8$ & $3 / 8$ \\
\hline PI-244019B / C. lanatus var. citroides & $6 / 8$ & $8 / 8$ & $2 / 8$ \\
\hline PI-195927 / C. colocynthis & $7 / 8$ & $8 / 8$ & $5 / 8$ \\
\hline Testemunha (Crimson Sweet) & $8 / 8$ & $8 / 8$ & $8 / 8$ \\
\hline
\end{tabular}

${ }^{1}$ Denominador $=$ Número de plantas inoculadas com o vírus em casa de vegetação; Numerador $=$ número de plantas infetadas pelo vírus sintomas diferenciados em forma e intensidade (Shukla et al., 1994). Segundo Lecoq \& Purcifull (1992), isolados de ZYMV, por exemplo, são extremamente variáveis, existindo estirpes que se diferenciam em sintomatologia e virulência. Já foram identificadas estirpes de ZYMV que induzem sintomas semelhantes ao PRSV-W e outras que se assemelham ao WMV (Lisa \& Lecoq, 1984). Este fato deve ser considerado na avaliação de genótipos para resistência aos referidos vírus, sendo preferível que os inóculos utilizados para seleção em condições controladas sejam provenientes da região onde os genótipos serão utilizados, evitando que a seleção ocorra envolvendo estirpe diferente daquela que se pretende controlar. Do contrário, a seleção realizada em condições de casa de vegetação poderá não ter eficiência em condições de campo. Dessa forma, plantas do acesso 87-029, não infetada quando inoculadas por PRSV-W, WMV e SYMV em casa de vegetação, foram infetadas por isolado desses vírus em condições de campo e, por tal razão, descartadas. Por outro lado, outra planta do mesmo acesso foi, também, descartada por haver sido infetada pelo WMV em condições de campo (Tabela 2). Entretanto, as demais plantas do mesmo acesso, assim como as plantas dos acessos 87-019, PI-244019A e 91080, que não foram infetadas em casa de vegetação pelos vírus correspondentes, mantiveram-se sem infecção dos vírus em condições de campo, sendo selecionadas para produzir progênies endogâmicas (PI-244019A, 87-029 e 91-080) e de polinização livre (87-019 e 87-029) e serem utilizadas para continuação do trabalho.

\section{Comportamento das Progênies}

Sete progênies avaliadas para resistência ao PRSV-W, em casa de vegetação, apresentaram um percentual de 20 a $100 \%$ de plantas resistentes (Tabela 3 ). As progênies avaliadas para resistência ao WMV, embora com amplitude menor de variação (60 a 100\%) apresentaram resultados semelhantes às avaliadas para resistência ao PRSV-W, com plantas selecionadas na maioria das progênies, excetuando-se apenas a progênie 01 , onde não ocorreu resistência ao vírus (Tabela 3). No que se refere ao ZYMV, não foi selecionada nenhuma progênie resistente (Tabela 3). A variação no percentual de plantas selecionadas nas progênies avaliadas para resistência ao PRSV-W, assim como naquelas avaliadas para resistência ao WMV, evidencia que existe um nível variado de segregação entre as mesmas para essa característica, podendo as progênies 05 e 08 se encontrar em homozigose para resistência ao PRSVW e a progênie 06 para resistência ao WMV. Outro fato a ser considerado é a diferença de comportamento entre as progênies 02 e 09, provenientes do acesso 87-019 e avaliadas para resistência ao PRSV-W (Tabela 3), demonstrando a importância de se monitorar gerações paternais e filiais quanto à expressão da reação à inoculação com vírus. De outra parte, visto que as progênies endogâmicas avaliadas foram submetidas ao mesmo número de auto-fecundações, considerando a ausência de plantas selecionadas nas progênies 01, 04, 07 e 08, avaliadas para resistência ao ZYMV, é possível postular que o número de alelos envolvidos no controle da 
TABELA 2 - Comportamento de 26 plantas de acessos de melancia (Citrullus lanatus e C. lanatus var. citroides) selecionados em condições casa de vegetação para Papaya ringspot virus, tipo watermelon (PRSV-W), Watermelon mosaic virus (WMV) e Zucchini yellow mosaic virus (ZYMV) e cultivados em campo. Estação Experimental de Bebedouro da Embrapa SemiÁrido, Petrolina, PE, 2002

\begin{tabular}{|c|c|c|c|c|}
\hline \multirow{2}{*}{ Acesso / espécie de Cîtrullus } & \multirow{2}{*}{$\begin{array}{c}\text { Resistentes a } \\
\text { Vírus* }\end{array}$} & \multicolumn{3}{|c|}{ Resultados sorologicos ${ }^{1}$} \\
\hline & & PRSV -W & WMV & ZYMV \\
\hline 87-019 / Citrullus lanatus & PRSV -W & - & - & $\mathrm{NT}^{2}$ \\
\hline 87-019 / C. lanatus & PRSV -W & - & - & - \\
\hline 87-019 / C. lanatus & WMV & - & - & - \\
\hline 87-019 / C. lanatus & WMV & - & - & - \\
\hline 87-019 / C. lanatus & WMV & - & - & - \\
\hline PI-244019A / C. lanatus var. citroides & PRSV -W & - & - & - \\
\hline PI-244019A / C. lanatus var. citroides & PRSV -W & - & - & - \\
\hline PI-244019A / C. lanatus var. citroides & WMV & - & - & - \\
\hline PI-244019A / C. lanatus var. citroides & ZYMV & - & - & - \\
\hline PI-244019A / C. lanatus var. citroides & ZYMV & - & - & - \\
\hline PI-244019A / C. lanatus var. citroides & ZYMV & - & - & - \\
\hline PI-244019A / C. lanatus var. citroides & ZYMV & - & - & - \\
\hline $87-029$ / C. lanatus & PRSV-W & - & + & + \\
\hline 87-029 / C. lanatus & PRSV -W & + & + & + \\
\hline 87-029 / C. lanatus & PRSV -W & - & + & - \\
\hline 87-029 / C. lanatus & PRSV -W & - & + & - \\
\hline 87-029 / C. lanatus & WMV & - & - & + \\
\hline 87-029 / C. lanatus & WMV & - & - & + \\
\hline 87-029 / C. lanatus & WMV & - & + & + \\
\hline 87-029 / C. lanatus & ZYMV & - & - & - \\
\hline 87-029 / C. lanatus & ZYMV & - & - & - \\
\hline 87-029 / C. lanatus & ZYMV & - & + & - \\
\hline 87-029 / C. lanatus & ZYMV & - & + & - \\
\hline 91-080 / C. lanatus & PRSV-W & - & - & - \\
\hline 91-080 / C. lanatus & PRSV -W & - & - & - \\
\hline $91-080$ / C. lanatus & PRSV -W & - & - & - \\
\hline Testemunha / Crimson Sweet & $\mathrm{S}^{* *}$ & + & + & + \\
\hline Testemunha / Crimson Sweet & $\mathrm{S}$ & + & + & + \\
\hline Testemunha/Crimson Sweet & $\mathrm{S}$ & + & + & + \\
\hline Testemunha / Crimson Sweet & $\mathrm{S}$ & + & + & + \\
\hline Testemunha / Crimson Sweet & $\mathrm{S}$ & + & + & + \\
\hline Testem unha / Crimson Sweet & $\mathrm{S}$ & + & + & + \\
\hline
\end{tabular}

TABELA 3 - Percentagem de plantas de progênies de melancia (Citrullus lanatus, C. colocynthis e C. lanatus var. citroides) selecionadas em casa de vegetação para resistência a Papaya ringspot virus, tipo watermelon (PRSV-W), Watermelon mosaic virus (WMV) e Zucchini yellow mosaic virus (ZYMV). LabVVeg/UFC. Fortaleza, CE, 2003

\begin{tabular}{|c|c|c|c|c|c|c|c|c|}
\hline \multirow{3}{*}{$\begin{array}{l}\text { Progênie/genitor } \\
\text { de melancía }\end{array}$} & \multirow[b]{3}{*}{ Espécie de Citrullus } & \multirow{3}{*}{$\begin{array}{l}\text { Tipo de } \\
\text { progênie }\end{array}$} & \multicolumn{6}{|c|}{ Plantas selecionadas por progênie } \\
\hline & & & \multicolumn{2}{|c|}{ PRSV -W } & \multicolumn{2}{|c|}{ WMV } & \multicolumn{2}{|c|}{ ZYMV } \\
\hline & & & $\begin{array}{c}\mathrm{N}^{a} \text { de } \\
\text { plantas } 1\end{array}$ & $\begin{array}{c}\% \text { de } \\
\text { plantas } \\
\text { resistentes }\end{array}$ & $\begin{array}{l}\mathrm{N}^{\mathrm{n}} \text { de } \\
\text { plantas }\end{array}$ & $\begin{array}{c}\% \text { de } \\
\text { plantas } \\
\text { resistentes }\end{array}$ & $\begin{array}{l}\mathrm{N}^{0} \text { de } \\
\text { plantas }\end{array}$ & $\begin{array}{c}\text { \% de } \\
\text { plantas } \\
\text { resistentes }\end{array}$ \\
\hline $01 / 87-029$ & Citrullus lanatus & Endogâmica & $\mathrm{NI}^{2}$ & NI & $0 / 8$ & 0 & $0 / 8$ & 0 \\
\hline $02 / 87-019$ & C. lanatus & & $5 / 6$ & 83 & $6 / 7$ & 85 & $\mathrm{NI}$ & NI \\
\hline $03 / 91-043$ & C. lanatus & Endogâmica & $5 / 7$ & 74 & $3 / 5$ & 60 & NI & $\mathrm{NI}$ \\
\hline 04 / PI -195927 & C. colocynthis & Endogâmica & $3 / 5$ & 60 & NI & NI & $\mathbf{0} / 7$ & 0 \\
\hline $05 / 91-080$ & C. lanatus & Endogâmica & $2 / 2$ & 100 & $5 / 7$ & 71 & $\mathrm{NI}$ & $\mathrm{NI}$ \\
\hline $06 / \mathrm{PI}-244019 \mathrm{~A}$ & C. lanatus var. citroides & & NI & NI & $7 / 7$ & 100 & $0 / 8$ & 0 \\
\hline $07 / 87-029$ & C. lanatus & Polinização livre & $2 / 3$ & 40 & NI & $\mathrm{NI}$ & $0 / 8$ & 0 \\
\hline 08 / PI-244019A & C. lanatus var. citroides & Endogâmica & $6 / 6$ & 100 & $4 / 5$ & 80 & NI & NI \\
\hline $09 / 87-019$ & C. lanatus & Endogâmica & $1 / 5$ & 20 & $5 / 8$ & 62 & $\mathrm{NI}$ & $\mathrm{NI}$ \\
\hline Testemunha & C. lanatus & Endogâmica & $0 / 8$ & 0 & $0 / 8$ & 0 & $0 / 8$ & 0 \\
\hline
\end{tabular}

${ }^{1}$ Numerador $=$ número de plantas não infetadas; Denominador $=$ número de plantas inoculadas; ${ }^{2} \mathrm{NI}=$ Progênie não inoculada com o respectivo vírus. 
resistência ao ZYMV nos genótipos avaliados é maior que o número de alelos envolvidos no controle da resistência ao PRSV-W e ao WMV, visto que nas avaliações em casa de vegetação dos acessos PI 244019A, 87-029 e PI-195927 que deram origem a essas progênies, ocorreu alta frequiência de plantas sem sintomas e negativas em Elisa para o ZYMV (Tabela 1). Apesar de não se dispor de muitas informações para a melancia, Azevedo et al. (2000) encontraram resistência a PRSV-W do tipo oligogênica, enquanto Wang et al. (1984) encontraram resistência ao mesmo vírus em pepino (Cucumis sativus L.) controlada por um alelo recessivo e Weeb (1979) relata a característica em meloeiro como monogênica dominante. No entanto, Danin-Polleg et al. (1997) encontraram três alelos de efeito complementar controlando resistência ao ZYMV em meloeiro. Estes relatos ressaltam a importância de se considerar cada genótipo individualmente nos programas de seleção de fontes de resistência aos três vírus, sendo necessária, a obtenção de progênies acompanhando a genealogia das mesmas. As plantas selecionadas foram levadas a campo para multiplicação e obtenção de mais uma geração de progênies endogâmicas.

\section{REFERÊNCIAS BIBLIOGRÁFICAS}

ALMEIDA, A.M.R. Técnicas sorológicas aplicadas à fitovirologia. In: Almeida, A.M.R. \& Lima J.A.A. (Eds.) Princípios e técnicas de diagnose aplicados em Fitovirologia. Publicações SBF. Fortaleza, CE. 2001. pp.33-62.

AZEVEDO, S.M., MALUF, W.R., OLIVEIRA, A.C.B., SOUSA, E.R., FARIA, M.V., MENEZES, C.B.M., MADEIRA, N., REZENDE, J.T.V., FREITAS, J.A.F. \& BENITES, F.R.G. Herança da resistência ao vírus da mancha anelar do mamoeiro-estirpe melancia (PRSV-W) em melancia. Horticultura Brasileira 18:634635. 2000 (Resumo).

BHARGAVA, B. \& BHARGAVA, K.S. Reaction of some cucurbit cultivars to seven strains of Watermelon mosaic virus. Indian Phytopathology 29:446-447. 1976.

COSTA, C.P. \& PINTO, C.A.B.P. Melhoramento de hortaliças: revisão. USP/ESALQ. Piracicaba, 1997.

DANIN-POLEG, Y., PARIS, R.S., COHEN, S., RABINOWITCH, H.D. \& KARCHI, Z. Oligogenic inheritance of resistance to zucchini yellow mosaic virus in melons. Euphytica 93:331-337. 1997.

DIAS, R.C.S., MACEDO, H.A. \& ANJOS, J.B. Técnica de polinização controlada em melancia e melão. Resumos, $14^{\circ}$ Encontro de Genética do Nordeste, Recife, PE. 1999. p.67.

FAO-FAOSTAT: Database Results. Disponível em: <http:// www.apps.fao.org>. Acesso em: 17 nov. 2003.

FERREIRA, M.A.J.F. Sistema reprodutivo e potencial para o melhoramento genético de uma população de melancia Citrullus lanatus (Thunb.) Matsum. \& Nakai. (Tese de Doutorado). Piracicaba. Escola Superior de Agricultura "Luiz de Queiroz", Universidade de São Paulo. 2000.

LECOQ, H. \& PURCIFULL, D.E. Biological variability of potyviruses, an example: Zucchini yellow mosaic virus. In: Barnett, O.W. (Ed.) Potyvirus taxonomy. Archives of Virology 5:229-234. 1992.

LIMA, J.A.A., QUEIROZ, M.A., RAMOS, N.F. \& GONÇALVES, M.F.B. Sintomas atípicos em frutos de meloeiro e de melancia ocasionados por Watermelon mosaic virus-2. Fitopatologia Brasileira 27:546. 2002.

LIMA, J.A.A., FLORINDO, M.I. \& SOUZA, A.E.B.A. An isolate of papaya ringspot virus obtained from naturally infected Luffa operculata. Fitopatologia Brasileira 22:213. 1997.

LISA, V. \& LECOQ, H. Zucchini yellow mosaic virus. CMI/AAB. Descriptions of Plant Virus. n. 282. 1984

OLIVEIRA, V.B., QUEIRÓZ, M.A. \& LIMA, J.A.A. Fontes de resistência aos principais potyvirus isolados de cucurbitáceas no Nordeste brasileiro. Horticultura Brasileira 20:589-592. 2002.

OLIVEIRA, V.B. Caracterização biológica e sorológica de isolados de potyvirus que infectam cucurbitáceas no Nordeste. (Dissertação de Mestrado). Fortaleza. Universidade Federal do Ceará. 2000.

OLIVEIRA, V.B., LIMA, J.A.A., VALE, C.C. \& PAIVA, W.O. Caracterização biológica e sorológica de isolados de potyvirus obtidos de cucurbitáceas no Nordeste brasileiro. Fitopatologia Brasileira 25:628-636. 2000.

QUEIRÓZ, M.A., SILVEIRA, L.M., TAVARES, S.C.H. \& COSTA, N.D. Identificação de fonte de resistência à queima das folhas por Alternaria em melancia. Anais, $16^{\circ}$ Encontro de Genética do Nordeste, São Luis, MA. 2002. p.114.

QUEIRÓZ, M.A de. Cucurbitáceas no semi-árido do Nordeste brasileiro: resgate, conservação e uso. Anais, $15^{\circ}$ Encontro sobre temas de Genética e Melhoramento, Piracicaba, SP. 1998. pp. 1-12. SILVA, B.R., PAZ, C.D., LIMA, J.A.A., PIO-RIBEIRO, G., NASCIMENTO, A.R.P. \& JUNIOR, A.R.A. Detecção de viroses em melancia no Submédio São Francisco, Fitopatologia Brasileira 25:448. 2000. (Resumo).

SILVEIRA, L.M. Recursos genéticos e melhoramento da melancia (Citrullus spp.). (Relatório de estágio curricular). Juazeiro. Departamento de Tecnologia e Ciências Sociais, Universidade do Estado da Bahia. 2002.

SHUKLA, D.D., WARD, C.W. \& BRUNT, A.A. Potyviridae CAB International. Wallingford. 1994.

WANG, Y.J., PROVVIDENTI, R. \& ROBINSON, R.W. Inheritance of resistance to Watermelon mosaic virus 1 in cucumber. HortScience 19:588. 1984. (Resumo)

WEEB, R.E. Inheritance of resistance to watermelon mosaic virus 1 in Cucumis melo L. HortScience 14:265-266. 1979.

YUKI, V.A. Cayaponia tibiricae. New host of zucchini yellow mosaic virus in Brazil. Plant Disease 83:486. 1999. (Note) 